\title{
Influence of lung donor agonal and warm ischemic times on early mortality: Analyses from the ISHLT DCD Lung Transplant Registry
}

\author{
Bronwyn Levvey, RN, ${ }^{a}$ Shaf Keshavjee, MD, ${ }^{\mathrm{b}}$ Marcelo Cypel, MD, ${ }^{\mathrm{b}}$ \\ Amanda Robinson, MS, ${ }^{c, *}$ Michael Erasmus, MD, ${ }^{d}$ Allan Glanville, MD, ${ }^{e}$ \\ Peter Hopkins, MD, ${ }^{f}$ Michael Musk, MD, ${ }^{g}$ Marshall Hertz, MD, ${ }^{h}$ Kenneth McCurry, MD, \\ Dirk Van Raemdonck, $M D^{j}$, and Gregory Snell, MD ${ }^{a}$ \\ From the ${ }^{a}$ Lung Transplant Service, The Alfred Hospital, Melbourne, Victoria, Australia; ${ }^{b}$ Toronto Lung Transplant Program, \\ Toronto General Hospital and Hospital for Sick Children, Toronto, Ontario, Canada; ${ }^{c}$ United Network for Organ Sharing, \\ Richmond, Virginia, USA; ${ }^{d}$ Department of Cardiology and Thoracic Surgery, Universitair Medisch Centrum, Groningen, The \\ Netherlands; ${ }^{e}$ Department of Thoracic Medicine and Lung Transplantation, St Vincent's Hospital, Sydney, New South Wales, \\ Australia; ${ }^{f}$ Queensland Lung Transplant Service, Prince Charles Hospital, Brisbane, Queensland, Australia; ${ }^{g}$ Lung Transplant \\ Unit, Fiona Stanley Hospital, Perth, Western Australia, Australia; ${ }^{h}$ Lung Transplant Program, University of Minnesota \\ Medical Center, Minneapolis, Minnesota, USA; ${ }^{i}$ Department of Thoracic and Cardiovascular Surgery, The Cleveland Clinic \\ Foundation, Cleveland, Ohio, USA; and the ${ }^{j}$ Department of Thoracic Surgery, University Hospitals, Leuven, Belgium.
}

\section{KEYWORDS:}

lung transplantation; donation after circulatory death; graft ischemia; mortality; organ donation; donor lung

\begin{abstract}
BACKGROUND: In this study we aimed to assess the impact of agonal time and warm ischemic time on early survival in Category III donation-after-circulatory-death (DCD) donor lung transplants (LTxs) using data reported to the International Society for Heart and Lung Transplantation (ISHLT) DCD Lung Transplant Registry.

METHODS: In this retrospective study, data were analyzed for 507 DCD LTxs done between January 2005 and June 2015. DCD lung donor agonal time (defined as withdrawal of life support to cessation of cardiac output) and warm ischemic time (WIT; defined as donor systolic blood pressure $<50 \mathrm{~mm}$ $\mathrm{Hg}$ to cold pulmonary artery flush) were divided into 3 clinical timing categories ( $<30$ minutes, 30 to 60 minutes, $>60$ minutes) and 3 tertiles. Univariate analysis was undertaken for all categorizations, and Day 30/Day 365 Kaplan-Meier survival rates were calculated and compared. Multivariable analysis included Cox proportional hazards regression models to estimate hazard of 365-day mortality.

RESULTS: Four hundred sixty-five and 301 DCD LTxs had data to analyze in the agonal and warm ischemic time groups, respectively. Day 30 and Day 365 post-transplant survival overall were $96 \%$ and $90 \%$, respectively, and not statistically different according to agonal or WIT category or tertile.

CONCLUSIONS: Current experience with DCD Category III LTx does not show a relationship between the duration of donor agonal phase or warm ischemic time up to 60 minutes and early survival. These results suggest the true limits of clinical DCD allograft warm ischemic times may not yet be reached. Global variations in clinical DCD practice are apparent. Continued accurate recording and analyses of DCD processes is warranted.

J Heart Lung Transplant 000;000:1-9

(c) 2018 International Society for Heart and Lung Transplantation. All rights reserved.
\end{abstract}


The introduction of donation-after-circulatory-death (DCD) lung donation for clinical transplantation has been shown in single-center, national, ${ }^{1,2}$ and international $^{3}$ registry reports and a meta-analysis ${ }^{4}$ to be practical and successful. In the 2015 International Society for Heart and Lung Transplantation (ISHLT) DCD Registry Report, Cypel et al compared 306 DCDs and 3,992 contemporaneous donation-after-brain-death (DBD) lung transplants (LTxs), and observed a comparable 61\% 5year survival in both arms. ${ }^{3}$

From these data, using the clinical approaches and timepoint definitions chosen by early DCD LTx investigators, ${ }^{1,5-8}$ it has become increasingly apparent that the lung allograft can reasonably tolerate DCD peri-mortem ischemic stress. Based on knowledge of experimental and clinical DCD liver and kidney transplantation, initial DCD LTx protocols have explored the notion that lungs would be definitely viable with cold flush perfused within 30 minutes after withdrawal of life-sustaining therapy (WLST). Subsequent clinical experience has shown that lungs are able to be successfully transplanted with cold flush perfused within 120 minutes post-WLST ${ }^{4-10}$ However, it had also been hypothesized that the lung may actually tolerate warm ischemia better than other solid organs, secondary to its low metabolic needs and the localized storage of oxygen (even in the form of post-mortem room air), and therefore that even longer ischemic times may be possible. $^{8}$

Recognizing the need to better understand the clinical importance and true practical limits of DCD lung ischemia, the 2015 DCD Registry Report ${ }^{3}$ indicated 6 time-points and 4 intervals as potentially key variables in the peri-mortem process, which may warrant further study. The donor agonal time and overall lung allograft warm ischemic time are of particular interest, as previous single-center series ${ }^{6,7}$ have suggested that extended times may predict early graft dysfunction. Conversely, although not able to report on early graft function specifically, the comprehensive 2015 DCD Registry Report ${ }^{3}$ did not show this potential effect to translate into an actual difference in 365-day survival.

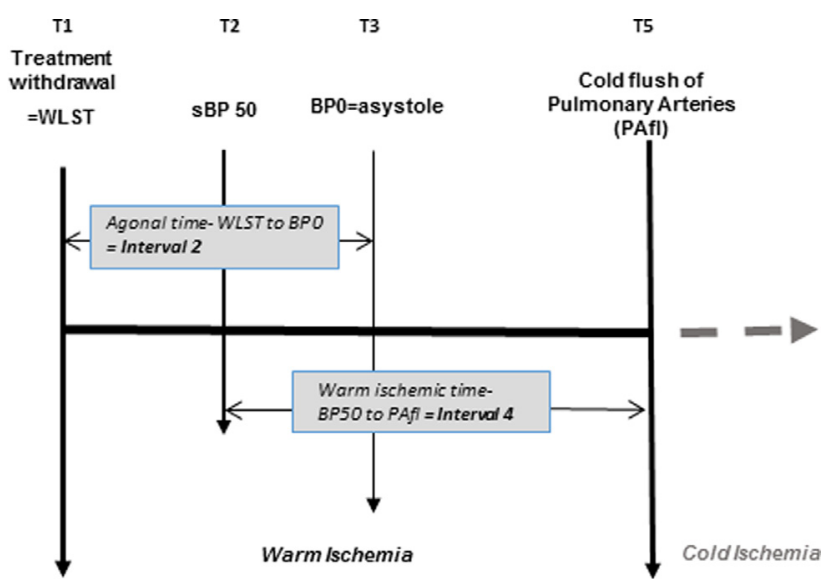

Figure 1 Schematic of the agonal (Interval 2) and warm ischemia (Interval 4) definitions evaluated in this study (other DCD intervals are also defined and detailed elsewhere). ${ }^{3}$
The primary aim of this study was to interrogate the ISHLT DCD Registry to determine in controlled DCD donors whether lung donor agonal time (defined as WLST to cessation of cardiac output with blood pressure [BP] no longer measurable [BP 0] = Interval 2; Figure 1) and warm ischemic time (defined as donor systolic blood pressure $<50 \mathrm{~mm} \mathrm{Hg}$ [sBP $<50$ ] to pulmonary artery cold flush [PAfl $]=$ Interval 4; Figure 1) impacted early (Day 30 and Day 365 ) post-LTx survival. ${ }^{3}$ The secondary aim was to explore simple clinical variables that may impact agonal time and warm ischemic time (WIT).

\section{Methods}

This retrospective study utilized data collected in the ISHLT DCD Registry from 12 participating centers, representing 5 countries on 3 continents. The participating centers were from Australia (The Alfred Hospital, Melbourne; St Vincent's Hospital, Sydney; Prince Charles Hospital, Brisbane; Fiona Stanley Hospital, Perth); Canada (Toronto General Hospital and Hospital for Sick Children, Toronto); Europe (UZ Gasthuisberg, Leuven, Belgium; Universitair Medisch Centrum Groningen, Groningen, The Netherlands); and the United States (Barnes Jewish Hospital, St. Louis; Cleveland Clinic, Cleveland; University of Minnesota Medical Center, Minneapolis; New York Presbyterian Hospital, Columbia University, New York; Brigham and Women's Hospital, Boston).

DCD utilization rates, WLST strategies, acceptable DCD timing limits, utilization of ex-vivo lung perfusion (EVLP) for donor lung assessment, and recipient allocation were performed according to individual center practice, noting that center protocols for all these strategies are not recorded in the ISHLT DCD LTx Registry. Of note, EVLP commences after donor lung retrieval, and therefore has no effect on the actual agonal time or WIT endpoints being evaluated in this study.

After submission of a study proposal to the ISHLT DCD Registry, pre-determined statistical analyses were performed by United Network for Organ Sharing (UNOS) data management staff under the auspices of the chair of the ISHLT DCD Registry. All Maastricht Category III DCD LTxs performed between January 2003 and June 2015 with data reported to the DCD Lung Transplant Registry were considered for these analyses. As the formal DCD Registry and definition of critical time intervals were not established at the time, all DCD LTxs reported before 2005 were missing the time-points of interest, thus the final cohort spanned January 2005 to June 2015. Of the 507 DCD LTxs that met the final inclusion criteria, 42 had unknown data for time of WLST reported, so they were excluded from the analysis of donor lung agonal time, and 206 DCD LTx had unknown data for sBP $<50$ reported and were excluded from the analysis of WIT.

Institutional investigational approval was facilitated through existing collaborations and agreements between the main ISHLT Registry, the DCD Lung Transplant Registry, and the various national contributing registries.

\section{Covariates}

Donor characteristics requested for the analyses included age, gender, body mass index (BMI), partial pressure of oxygen $\left(\mathrm{PO}_{2}\right)$, use of inotropes, mechanism of donor death, and endotracheal extubation status during WLST. Recipient characteristics included age, gender, BMI, medical 
diagnosis, requirement for extracorporeal membrane oxygenation (ECMO) and/or ventilation pre-LTx, and length of hospital stay. Other characteristics analyzed included transplant type (single vs bilateral), year of transplant, and continent.

\section{Univariate analyses of effects of covariates on agonal time and WIT}

Both the agonal time (Interval 2) and WIT (Interval 4) cohorts were categorized using 2 methods. The first divided the responses into 3 groups based on common clinical practice: $<30$ minutes; 30 to 60 minutes; and $>60$ minutes. In addition, both responses were broken into 3 equally populated groups using the $33 \mathrm{rd}$ and 67 th percentiles for the continuous response, hereafter referred to as tertiles. Analyses were performed separately for all categorizations of both responses.

The distributions of continuous covariates are reported as the median and 25 th and 75 th percentiles. Overall comparisons of these variables across all response categories were performed using the Kruskal-Wallis test. Pairwise comparisons were conducted using Wilcoxon's rank sum test and were adjusted using the Bonferroni method.

The distributions of categorical covariates are reported as percentages. These variables were compared across all response categories using the chi-square test if there were sufficient numbers. In the cases where the chi-square test was not appropriate, Fisher's exact test was used. Pairwise comparisons of these variables were also conducted using the same test as that used in the overall comparison. Again, these pairwise comparisons were adjusted using the Bonferroni method.

\section{Univariate analyses of covariates on survival}

Survival rates were compared across all 3 categories for agonal time (Interval 2) simultaneously (i.e., an overall $p$-value, testing whether at least 1 of the 3 time categories differs, but does not identify which one[s] differ) using a log rank test. Separately, the characteristics were compared across all 3 categories for WIT (Interval 4) simultaneously.

In addition, pairwise comparisons of survival between each pair of time categories (e.g., $<30$ minutes vs 30 to 60 minutes, Tertile 1 vs Tertile 3 ) were performed. The survival curves for paired categories were compared using a log rank test. If the survival curves crossed, the log rank tests were not appropriate and a Renyi test was used instead. Pairwise comparisons of 30- and 365-day survival rates were performed using complementary log-log transformations of the survival estimates (Cloglog). Adjustments were made for pairwise comparisons using the Bonferroni method. Cloglog tests could not be performed in cases where at least 1 of the estimated rates was $100 \%$ survival.

Thirty- and 365-day Kaplan-Meier survival rates were calculated along with their corresponding $95 \%$ confidence intervals for all categories of all responses. $p<0.05$ was considered statistically significant.

\section{Multivariable survival analyses}

Those covariates with a high proportion $(>80 \%)$ of missing values (donor $\mathrm{PO}_{2}$, requirement for ECMO and/or ventilation pre-LTx, length of hospital stay) were excluded from the multivariable analyses of these data. Multiple imputation was used to replace the missing values, with 10 imputations run.

After imputing the data, a Cox proportional hazards regression model was fit to estimate the hazard of death within 1 year. All continuous variables were included in the model as a restricted cubic spline with 3 knots. All covariates of interest were initially included in the model. A backward selection process was then used to eliminate variables until those remaining all had $p$-values $<0.10$. The time interval of interest (agonal time $=$ Interval 2, WIT $=$ Interval 4) was included regardless of significance.

Estimates and $95 \%$ confidence intervals (CIs) for hazard ratios (HRs) were calculated.

\section{Results}

From 507 DCD LTxs, agonal time (Interval 2) could be calculated in 465 cases and WIT (Interval 4) could be calculated in 301 cases. The distribution of these variables is shown in Figure 2a and b, respectively. Overall, 92\% of DCD donors were extubated at WLST, and there was no significant difference in the proportion of extubated donors comparing time intervals or tertiles. Of note, $84.5 \%$ of the DCD donors reached asystole in $\leq 30$ minutes, $96.5 \%$ in $\leq 60$ minutes post-WLST, with only $3.5 \%$ taking $>60$ minutes to reach asystole. DCD lungs were utilized in 5 cases where the agonal time was between 100 and 150 minutes. Of the 301 LTxs where the WIT interval could be calculated, $90 \%$ of cases had a WIT of $\leq 30$ minutes and $99 \%$ a WIT of $\leq 75$ minutes.

\section{Univariate analyses of effects of covariates on agonal time and WIT}

Tables 1 and 2 show distribution and comparison data of donor and recipient characteristics for agonal time characterized by 30-minute intervals and tertiles, respectively. Specific significant pairwise comparisons are identified in the last columns of both tables. A shorter agonal time was associated with donor inotrope cessation, cerebrovascular accident (CVA) as the cause of donor death, and non-North American donor. There was no association between donor BMI and length of agonal time. Longer agonal time was associated with being a DCD donor in North America and receiving a single $\mathrm{LTX}$.

Tables 3 and 4 show distribution and comparison data of donor and recipient characteristics for WIT characterized by 30-minute intervals and tertiles, respectively. Specific significant pairwise comparisons are identified in the last column of both tables. A shorter WIT was associated with donor inotrope cessation, interstitial lung disease as the transplant indication, North American donor, and receiving a single LTX. 


\section{a) Agonal time distribution}

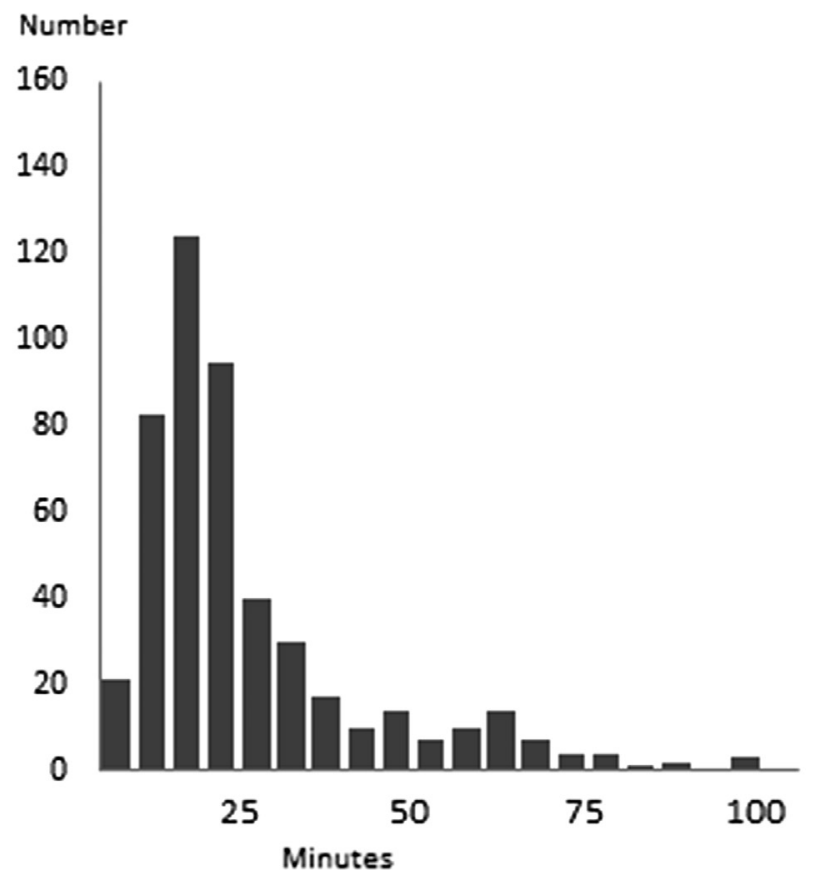

\section{b) Warm ischemic time distribution}

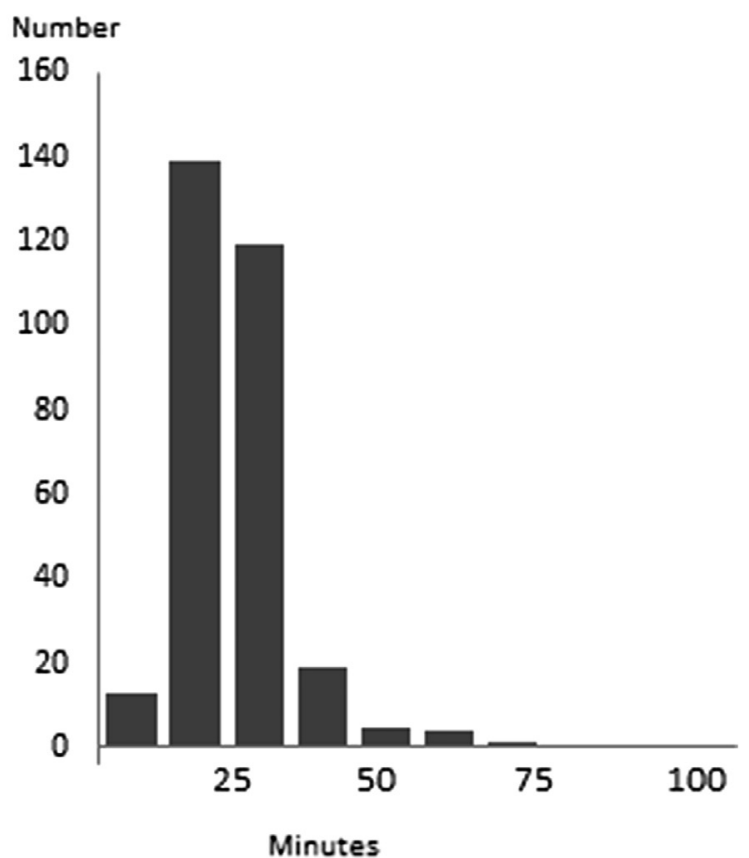

Figure 2 Frequency distributions of agonal time (a) and warm ischemic time (WIT) (b).

\section{Effect of agonal time and WIT on 1-year survival}

Figures 3 and 4 demonstrate Kaplan-Meier survival rate comparisons categorized by 30 -minute intervals and tertiles for agonal time and WIT, respectively. For all analyses there was no statistically significant difference in 30- and 365-day survival rates across all pairings of agonal time or WIT categories, nor the overall survival curves.

Table 1 Agonal Time by 30-Minute Time Groups $(n=465)$

\begin{tabular}{|c|c|c|c|c|c|}
\hline Variable & $\begin{array}{l}<30 \text { min } \\
(n=387)\end{array}$ & $\begin{array}{l}30-60 \text { min } \\
(n=62)\end{array}$ & $\begin{array}{l}>60 \text { min } \\
(n=16)\end{array}$ & $p$-value & Pairwise comparisons of groups \\
\hline Donor age, in years [median (IQR] & 47 (33 to 55) & 48 (37 to 55$)$ & $44(37$ to 54$)$ & 0.95 & $p=\mathrm{ns}$ \\
\hline Donor male gender (\%) & 62 & 63 & 44 & 0.33 & $p=\mathrm{ns}$ \\
\hline Donor inotropes (yes) (\%) & 64 & 36 & 33 & 0.01 & $<30-\min$ vs $30-60-\min$ groups, $p=0.03$ \\
\hline Donor BMI [median (IQR] & 25 (23 to 28$)$ & 25 (22 to 27$)$ & 25 (22 to 27$)$ & 0.53 & $p=\mathrm{ns}$ \\
\hline Donor cause of death (\%) & & & & 0.06 & $<30-\min$ vs $30-60-\min$ groups, $p=0.05$ \\
\hline Anoxia & 29 & 35 & 44 & & \\
\hline CVA & 39 & 24 & 31 & & \\
\hline Head trauma & 26 & 25 & 18 & & \\
\hline Other & 6 & 15 & 6 & & \\
\hline Recipient age, in years [median (IQR)] & 54 (38 to 61$)$ & 55 (40 to 61$)$ & $58(54$ to 66$)$ & 0.11 & $p=\mathrm{ns}$ \\
\hline Recipient male gender (\%) & 55 & 60 & 63 & 0.66 & $p=\mathrm{ns}$ \\
\hline Bilateral LTx (\%) & 90 & 84 & 81 & 0.15 & $p=\mathrm{ns}$ \\
\hline Recipient diagnosis (\%) & & & & 0.71 & $p=\mathrm{ns}$ \\
\hline $\mathrm{CF}$ & 20 & 21 & 13 & & \\
\hline COPD & 34 & 31 & 25 & & \\
\hline ILD & 19 & 14 & 31 & & \\
\hline Other & 27 & 34 & 31 & & \\
\hline Continent of $\mathrm{Tx}(\%)$ & & & & 0.01 & $<30-\min$ vs $30-60-\min$ groups, $p=0.07$ \\
\hline Europe & 34 & 25 & 13 & & \\
\hline North America & 28 & 45 & 56 & & \\
\hline Other & 38 & 29 & 31 & & \\
\hline
\end{tabular}

BMI, body mass index; CF, cystic fibrosis; COPD, chronic obstructive pulmonary disease; CVA, cerebrovascular accident; ILD, interstitial lung disease; IQR, interquartile range; LTx, lung transplant; min, minutes; ns, not statistically significant; Tx transplant. 
Table 2 Agonal Time by Tertiles $(n=465)$

\begin{tabular}{|c|c|c|c|c|c|}
\hline Variable & $\begin{array}{l}\text { Tertile } 1: 0 \text { to } \\
13 \min (n=172)\end{array}$ & $\begin{array}{l}\text { Tertile } 2: 14 \text { to } \\
19 \min (n=145)\end{array}$ & $\begin{array}{l}\text { Tertile } 3: 20 \text { to } \\
149 \min (n=148)\end{array}$ & $p$-value & Pairwise comparisons of tertiles \\
\hline $\begin{array}{l}\text { Donor age, in years } \\
\text { [median [IQR]) }\end{array}$ & 47 (30 to 56$)$ & 46 (36 to 55$)$ & 49 (36 to 55$)$ & 0.70 & $p=\mathrm{ns}$ \\
\hline Donor male gender (\%) & 68 & 59 & 57 & 0.10 & $p=\mathrm{ns}$ \\
\hline Donor inotropes (yes) (\%) & 71 & 69 & 33 & 0.01 & $p=\mathrm{ns}$ \\
\hline Donor BMI [medan (IQR)] & 25 (23 to 29$)$ & 25 (23 to 28$)$ & 25 (22 to 27 ) & 0.16 & $p=\mathrm{ns}$ \\
\hline Donor cause of death (\%) & & & & 0.05 & Tertile 1 vs Tertile 2 groups, $p=0.04$ \\
\hline Anoxia & 33 & 26 & 31 & & \\
\hline CVA & 31 & 48 & 33 & & \\
\hline Head trauma & 28 & 21 & 28 & & \\
\hline Other & 8 & 4 & 8 & & \\
\hline $\begin{array}{l}\text { Recipient age, in years } \\
\text { [median (IQR)] }\end{array}$ & 54 (43 to 61$)$ & 52 (32 to 59$)$ & 57 (44 to 62 ) & $<0.01$ & $p=\mathrm{ns}$ \\
\hline Recipient male gender (\%) & 56 & 58 & 53 & 0.65 & $p=\mathrm{ns}$ \\
\hline Bilateral LTx (\%) & 94 & 93 & 79 & $<0.01$ & $\begin{array}{l}\text { Tertile } 1 \text { vs Tertile } 3, p<0.01 \\
\text { Tertile } 2 \text { vs Tertile } 3, p<0.01\end{array}$ \\
\hline Recipient diagnosis (\%) & & & & 0.08 & Tertile 1 vs Tertile 2 groups, $p=0.06$ \\
\hline CF & 15 & 27 & 18 & & \\
\hline COPD & 40 & 27 & 32 & & \\
\hline ILD & 16 & 20 & 22 & & \\
\hline Other & 29 & 26 & 28 & & \\
\hline Continent of $\mathrm{Tx}(\%)$ & & & & $<0.01$ & $\begin{array}{l}\text { Tertile } 1 \text { vs Tertile } 3, p<0.01 \\
\text { Tertile } 2 \text { vs Tertile } 3, p<0.01\end{array}$ \\
\hline Europe & 35 & 32 & 30 & & \\
\hline North America & 23 & 25 & 47 & & \\
\hline Other & 42 & 43 & 23 & & \\
\hline
\end{tabular}

BMI, body mass index; CF, cystic fibrosis; COPD, chronic obstructive pulmonary disease; CVA, cerebrovascular accident; ILD, interstitial lung disease; IQR, interquartile range; LTx, lung transplant; min, minutes; ns, not statistically significant; Tx transplant.

Table 3 Warm Ischemic Time by 30-minute Time Groups $(n=301)$

\begin{tabular}{|c|c|c|c|c|c|}
\hline Variable & $\begin{array}{l}<30 \text { min } \\
(n=263)\end{array}$ & $\begin{array}{l}30-60 \text { min } \\
(n=35)\end{array}$ & $\begin{array}{l}>60 \text { min } \\
(n=3)\end{array}$ & $p$-value & Pairwise comparisons of groups \\
\hline Donor age, in years [median (IQR)] & $46(31$ to 55$)$ & 45 (37 to 60$)$ & 18 (17 to 19$)$ & 0.03 & $30-60 \min$ vs $>60 \min , p=0.04$ \\
\hline Donor male gender (\%) & 64 & 62 & 100 & 0.66 & $p=\mathrm{ns}$ \\
\hline Donor Inotropes (yes) (\%) & 64 & 50 & 67 & 0.49 & $p=\mathrm{ns}$ \\
\hline Donor cause of death (\%) & & & & 0.72 & $p=\mathrm{ns}$ \\
\hline Anoxia & 35 & 29 & 0 & & \\
\hline CVA & 32 & 40 & 33 & & \\
\hline Head trauma & 26 & 25 & 66 & & \\
\hline Other & 7 & 6 & 0 & & \\
\hline Recipient age, inyears [median (IQR)] & 55 (39 to 62$)$ & $52(35$ to 56$)$ & 60 (58 to 63$)$ & 0.09 & $p=\mathrm{ns}$ \\
\hline Recipient male gender (\%) & 57 & 51 & 66 & 0.82 & $p=\mathrm{ns}$ \\
\hline Bilateral LTx (\%) & 89 & 91 & 100 & 0.84 & $p=\mathrm{ns}$ \\
\hline Recipient diagnosis (\%) & & & & $<0.01$ & $<30 \min$ vs $30-60 \min , p=0.01$ \\
\hline $\mathrm{CF}$ & 22 & 31 & 0 & & \\
\hline COPD & 32 & 20 & 67 & & \\
\hline ILD & 24 & 6 & 0 & & \\
\hline Other & 22 & 43 & 33 & & \\
\hline Continent (\%) & & & & $<0.01$ & $<30 \min$ vs $30-60 \min , p<0.01$ \\
\hline Europe & 8 & 37 & 0 & & \\
\hline North America & 37 & 14 & 33 & & \\
\hline Other & 54 & 49 & 67 & & \\
\hline
\end{tabular}

BMI, body mass index; CF, cystic fibrosis; COPD, chronic obstructive pulmonary disease; CVA, cerebrovascular accident; ILD, interstitial lung disease; IQR, interquartile range; LTx, lung transplant; min, minutes; ns, not statistically significant; Tx transplant. 
Table 4 Warm Ischemic Time by Tertileiles $(n=301)$

\begin{tabular}{|c|c|c|c|c|c|}
\hline Variable & $\begin{array}{l}\text { Tertile } 1: 3 \text { to } \\
18 \min (n=110)\end{array}$ & $\begin{array}{l}\text { Tertile 2: } 19 \text { to } \\
23 \min (n=95)\end{array}$ & $\begin{array}{l}\text { Tertile } 3: 24 \text { to } \\
297 \min (n=96)\end{array}$ & $p$-value & Pairwise comparisons of tertiles \\
\hline Donor age, in years [median (IQR)] & $44(28$ to 54$)$ & $48(33$ to 56$)$ & $46(37$ to 56$)$ & 0.20 & $p=\mathrm{ns}$ \\
\hline Donor male gender (\%) & 66 & 60 & 67 & 0.57 & $p=\mathrm{ns}$ \\
\hline Donor inotropes (yes) (\%) & 49 & 69 & 71 & 0.02 & $p=\mathrm{ns}$ \\
\hline \multicolumn{6}{|l|}{ Donor cause of death (\%) } \\
\hline Anoxia & 34 & 39 & 29 & 0.60 & $p=\mathrm{ns}$ \\
\hline CVA & 29 & 32 & 40 & & \\
\hline Head trauma & 29 & 23 & 26 & & \\
\hline Other & 8 & 6 & 5 & & \\
\hline Recipient age, in years [median (IQR)] & 56 (40 to 61$)$ & 53 (38 to 62$)$ & 54 (39 to 62$)$ & 0.70 & $p=\mathrm{ns}$ \\
\hline Recipient male gender (\%) & 57 & 55 & 58 & 0.87 & $p=\mathrm{ns}$ \\
\hline Bilateral LTx (\%) & 78 & 96 & 95 & $<0.01$ & $\begin{array}{l}\text { Tertile } 1 \text { vs Tertile } 2, p<0.01 \\
\text { Tertile } 1 \text { vs Tertile, } 3 p<0.01\end{array}$ \\
\hline Recipient diagnosis (\%) & & & & 0.06 & $p=\mathrm{ns}$ \\
\hline $\mathrm{CF}$ & 21 & 21 & 26 & & \\
\hline COPD & 27 & 37 & 30 & & \\
\hline ILD & 30 & 20 & 13 & & \\
\hline Other & 22 & 22 & 31 & & \\
\hline Continent (\%) & & & & $<0.01$ & $\begin{array}{l}\text { Tertile } 1 \text { vs Tertile } 2, p=0.02 \\
\text { Tertile } 1 \text { vs Tertile } 3, p<0.01\end{array}$ \\
\hline Europe & 10 & 6 & 19 & & \\
\hline North America & 48 & 30 & 24 & & \\
\hline Other & 42 & 64 & 57 & & \\
\hline
\end{tabular}

BMI, body mass index; CF, cystic fibrosis; COPD, chronic obstructive pulmonary disease; CVA, cerebrovascular accident; ILD, interstitial lung disease; IQR, interquartile range; LTx, lung transplant; min, minutes; ns, not statistically significant; Tx transplant.

\section{Multivariable analyses of causes of 1-year mortality}

Covariates included in the initial models, in addition to agonal time and WIT recipient factors, were age, gender, BMI, and medical diagnosis. Donor factors were age, gender, BMI, inotropes, cause of death, and endotracheal extubation status. Transplant factors were year of LTx, procedure type, and continent. A modified backward selection procedure was used to determine which covariates were to be included in the final model.

In the multivariable model evaluating agonal time by 30 minute intervals, variables associated with an increased

\section{a) Survival comparisons by timegroups}

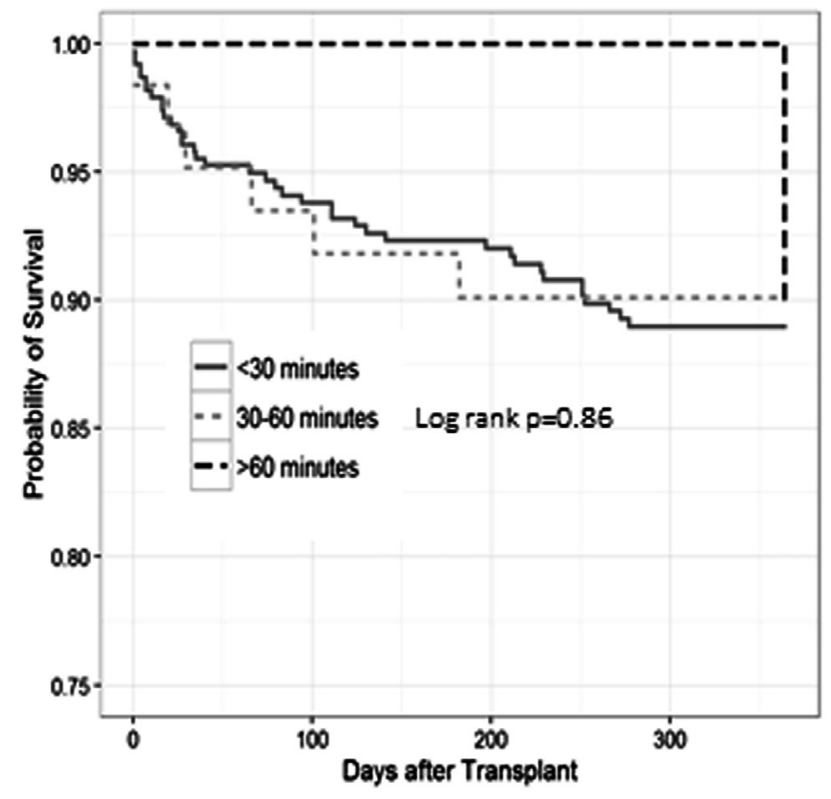

\section{b) Survival comparisons by tertiles}

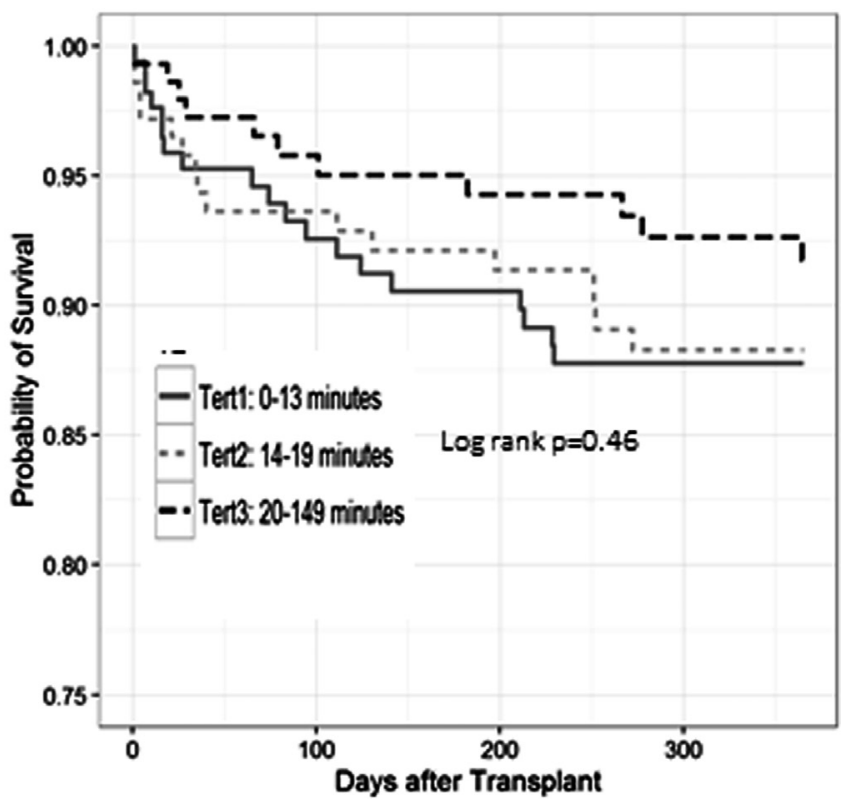

Figure 3 Survival at 365 days according to agonal time: (a) time groups and (b) tertiles. 
a) Survival comparisons by timegroups

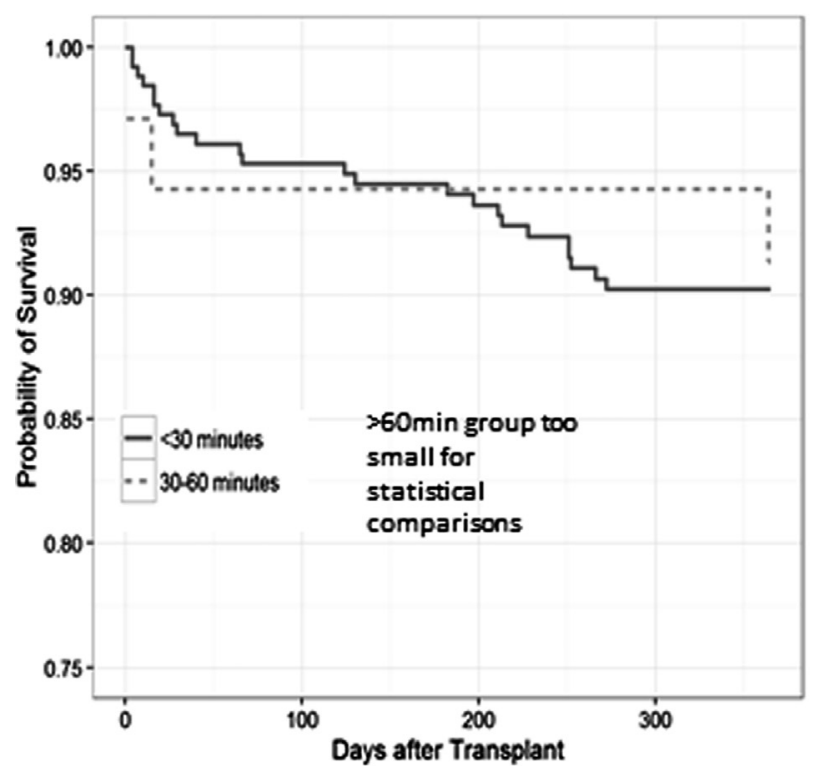

b) Survival comparisons by tertiles

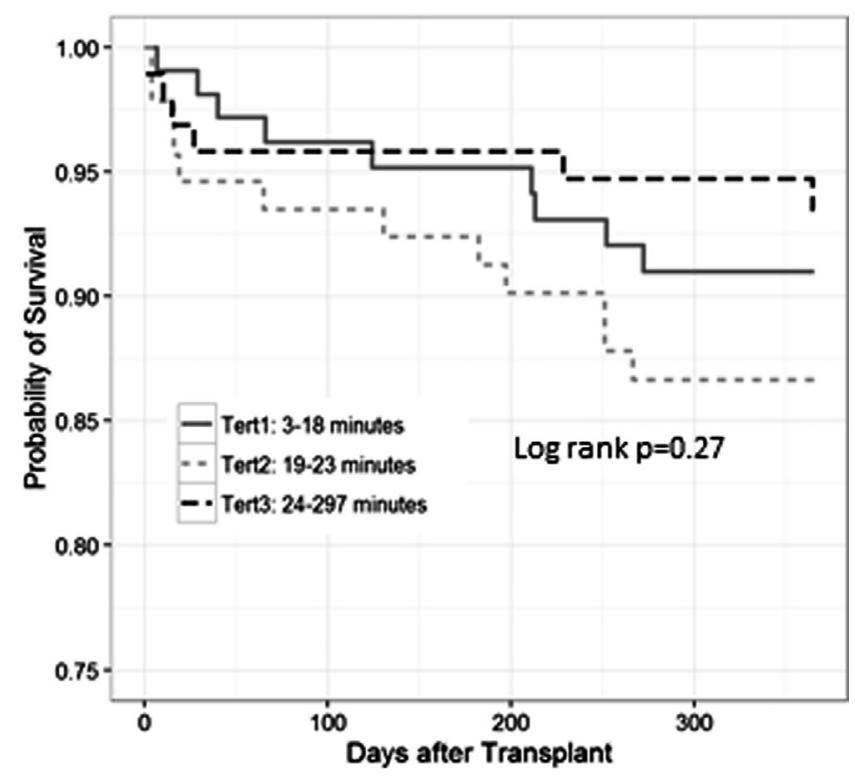

Figure 4 Survival at 365 days according to warm ischemic time (WIT): (a) time groups and (b) tertiles.

hazard of death included: donor cause of death other than anoxia or head trauma as compared with CVA (HR 4.1, 95\% CI 1.6 to $10.6, p=0.003$ ) and recipient diagnosis of interstitial lung disease (HR 4.1, 95\% CI 1.7 to 9.9, $p=0.0015)$ when compared with emphysema/chronic obstructive pulmonary disease (COPD). Results were similar in the tertile-based model with donor cause of death other than CVA (HR $4.095 \%$ CI 1.6 to $10.23, p=0.004$ ) and recipient diagnosis of interstitial lung disease (HR 3.5, 95\% CI 1.5 to $8.3, p=0.004$ ) again being significant. Agonal time was not associated with 365-day mortality.

The multivariable model evaluating WIT 30-minute intervals and tertiles showed a 2.9-fold variability in the hazard of 365-day death to be associated with continent of transplant (HR 2.9, 95\% CI 1.2 to 7.1, $p=0.017$; and HR $2.9,95 \%$ CI 1.2 to $6.9, p=0.018)$ and the presence of donor inotropes (HR 3.4, CI 95\% 1.1 to 11.0, $p=0.042$; and HR $3.4,95 \%$ CI 1.0 to $11.5, p=0.045$ ), respectively. WIT was not associated with 365-day mortality.

\section{Discussion}

With a 96\% 30-day and 90\% 365-day post-operative survival, these analyses confirm the clinical utility of DCD LTx. From the data reported to the ISHLT DCD Registry, univariate and multivariable analyses of agonal time (Interval2) and WIT (Interval4), calculated for this cohort, do not influence the30-day and 365-day survival. This suggests that, at least for controlled DCD LTx, the limits of tolerability of agonal and warm ischemia are beyond 60 minutes.

Although a recent case report has confirmed the success of extending agonal time to enable successful DCD lung retrieval,${ }^{10}$ in the present report we found that $84 \%$ of donor organs used for DCD LTx reached asystole in $<30$ minutes. Notwithstanding, 7 of the 9 centers providing data to the 2015 DCD Registry Report ${ }^{3}$ had a policy of agonal time limit of 90 to 180 minutes, confirming a clear level of comfort to at least consider lungs beyond the historic 60minute agonal time limit.

These analyses also continue to point to the importance of donor, recipient, and procedural factors in DCD outcomes. The various causes of donor death may influence the hormonal and metabolic milieu, potentially with a CVA being less damaging than, for example, brain trauma. ${ }^{3}$ Donor organs requiring inotropes for hypotension may be a marker of fluid balance challenges, sepsis, or an early phase of inflammatory multiorgan failure-all of which may adversely influence allograft function and lead to secondary problems. Reflecting standard DBD donor LTx outcomes, a recipient diagnosis of interstitial lung disease usually does reflect a higher risk recipient.

In the multivariable survival analyses controlled for WIT, the almost 3-fold variability of 365-day mortality related to the continent on which the DCD LTx was done (5.7\% vs $15.5 \%$ vs $7.1 \%)$ most likely represents differences in donor selection and management, allocation policies, and utilization rates of other technologies such as EVLP and ECMO support pre-/post-LTx. These confounding differences may be associated with diversity of LTx outcomes themselves and at least partially explain why there remains international variation in the adoption of DCD LTx. ${ }^{2,11,12}$ On the other hand, recent work may challenge this, as Mooney et al noted that modeling of US Scientific Registry of Transplant Recipient data confirmed a 10-fold higher utilization rate of equivalent DBD over DCD donor lungs ( $21 \%$ vs $2.1 \%$ ), with no difference in adjusted 5-year survival outcomes. ${ }^{13}$ It is necessary to continue to explore and study these factors as further modifications may provide a path to superior DCD (and even DBD) LTx outcomes.

With the absence of appropriate Registry data fields to record information on EVLP utilization, it was not possible to determine the utility and impact of EVLP in DCD LTx cases evaluated in this study. Although some centers have reported using EVLP for DCD lungs after extended agonal 
or WIT periods, we did not have the data available in this study to evaluate the role of EVLP for this indication, and its role remains the subject of ongoing debate. ${ }^{14,15}$

The conclusions about cautiously extending ischemic times can only apply to the agonal (Interval 2) and WIT (Interval 4) definitions used in this study. It is also notable that further cold and warm ischemic time intervals follow the cold PAfl. Therefore, as recognized previously in the DCD LTx literature, ${ }^{3,9}$ there are multiple possible definitions of allograft ischemia. In particular, the timing of reinflation/ventilation (T3) prior to PAfl reperfusion' may be relevant. ${ }^{9,16}$ Reinstituting ventilation assumes even greater importance when considering uncontrolled Category 1 and 2 DCD LTx, as it can to be applied clinically before PAfl in many cases. ${ }^{17}$ The ISHLT LTx community needs to encourage centers to participate in contributing data to the DCD LTx Registry, and to recognize the importance of recording and reporting all standardized time-points identified in the 2015 DCD LTx Registry report. ${ }^{3}$ In addition, it would be ideal to include specific data on PGD and $\mathrm{CLAD}^{18,19}$ as alternate study end-points, combined with longer term follow-up, for future DCD LTx outcome analyses.

\section{Study limitations}

The strength of these analyses is the size of the cohort and the use of mortality as a hard end-point, but there are significant limitations as well. Unlike the general ISHLT LTx Registry, the ISHLT DCD LTx Registry currently includes only $21 \%$ North American cases. Data entry for many of the registry data fields is compulsory in the United States, whereas non-North American centers voluntarily report data that are typically exported from local or national registries.

Missing data in key donor and recipient fields plus the paucity of PGD and CLAD data reported in the overall ISHLT Registry can present major problems when undertaking a study interrogating data from the ISHLT DCD LTx Registry. A lack of data completeness and quality in both the ISHLT DCD LTx Registry and overall Registry was not evident until this specific DCD research question was asked. As this study was primarily an ISHLT DCD Registry data analysis, the data could only be accessed and analyzed by UNOS statisticians, and funding limitations for the project limited the analysis to the original study hypothesis-despite investigators seeking further data exploration and additional outcome analyses.

The impact of different organ preservation strategies, EVLP, and extracorporeal lung support on DCD outcomes could not be evaluated due to the absence of relevant data fields collected in the ISHLT registries, but it should be considered in future studies. Similarly, the effect of variable DCD ischemia on PGD, CLAD, and long-term mortality was not evaluable, but remains relevant for future analyses. Separate analyses by nationality or individual LTx center were not possible utilizing ISHLT Registry data, as these data are pooled and analyzed by continent only. Our study did include centers with both minimal and extensive DCD experience and, in displaying pooled data only, variations in clinical protocols and resultant outcomes may have been underestimated. Future analyses including long-term outcome data from all centers from around the world with DCD LTx experience, and ensuring that the key DCD data points are collected, resourced for analyses, and reported, would broaden the applicability of further DCD LTx Registry findings.

In conclusion, controlled DCD LTx continues to demonstrate quality outcomes with no obvious effect of donor agonal time and WIT on 30- and 365-day survival. Our findings suggest that, for Category III DCD LTx, the limits of tolerability of agonal time and warm ischemia are beyond 60 minutes. Cautious utilization of donors with longer agonal periods or WITs appears possible. Global variations in clinical DCD practice are apparent. Continued accurate recording and analyses of all DCD processes are warranted.

\section{Disclosure statement}

S.K and M.C are founders and shareholders of XOR Labs Toronto and Perfusix, Canada, and are consultants for Lung Bioengineering. The remaining authors have no conflicts of interest to disclose.

\section{Supplementary materials}

Supplementary material associated with this article can be found, in the online version, at doi:10.1016/j.healun.2018. 08.006 .

\section{References}

1. Levvey BJ, Harkess M, Hopkins P, et al. Excellent clinical outcomes from a national donation after cardiac death lung transplant collaborative. Am J Transplant 2012;12:2406-13.

2. Mason DP, Thuita L, Alster JM, et al. Should lung transplantation be performed using donation after cardiac death? The United States experience. J Thorac Cardiovasc Surg 2008;136:1061-6.

3. Cypel M, Levvey BJ, Van Raemdonck D, et al. ISHLT Donation after Circulatory Death Registry Report. J Heart Lung Transplant 2015;74:1278-82.

4. Krutsinger D, Reed R, Blevins A, et al. Lung transplantation from donation after cardiocirculatory death: a systematic review and metaanalysis. J Heart Lung Transplant 2015;34:675-84.

5. Love RB, Stringham JC, Chomiak PN, et al. Successful lung transplantation using a non-heart beating donor. J Heart Lung Transplant 1995;14(suppl):S88.

6. Cypel M, Sato M, Yildirim E, et al. Initial experience with lung donation after cardiocirculatory death in Canada. J Heart Lung Transplant 2009;28:753-8.

7. Snell GI, Levvey BJ, McEgan R, et al. Early lung transplantation success utilizing controlled donation after cardiac death donors. Am J Transplant 2008;8:1282-9.

8. Egan TM, Lambert CJ, Reddick R, et al. A strategy to increase the donor pool: use of cadaveric lungs for transplantation. Ann Thorac Surg 1991;52:1113-20.

9. Levvey BJ, Westall GP, Kotsimbos T, et al. Definitions of warm ischemic time when utilizing controlled donation after cardiac death lung donors. Transplantation 2008;86:1702-6. 
10. Reeb J, Keshavjee S, Cypel M. Successful lung transplantation from a donation after cardiocirculatory death donor taking more than 120 minutes to cardiac arrest after withdrawal of life support therapies. J Heart Lung Transplant 2016;35:258-9.

11. Cypel M, Levvey BJ, Van Raemdonck D, et al. Lung transplantation using controlled donation after circulatory death donors: trials and tribulations. J Heart Lung Transplant 2016;35:146-7.

12. Dark JH, Egan TM. Lungs from the controlled donation after circulatory determination of death donor: perspectives from the United States and beyond. Am J Transplant 2016;16:1047-8.

13. Mooney JJ, Hedlin H, Mohabir PK, et al. Lung quality and utilization in controlled donation after circulatory determination of death within the United States. Am J Transplant 2016;16:1207-15.

14. Machuca TN, Mercier O, Collaud S, et al. Lung transplantation with donation after circulatory determination of death donors and the impact of ex vivo lung perfusion. Am J Transplant 2015;15:993-1002.
15. Snell G, Levvey B, Westall G. The changing landscape of lung donation for transplantation. Am J Transplant 2015;14:859-60.

16. Miyoshi K, Oto T, Otani S, et al. Effect of donor pre-mortem hypoxia and hypotension on graft function and start of warm ischemia in donation after cardiac death lung transplantation. J Heart Lung Transplant 2011;30:445-51.

17. Egan T. Lung transplant from an uncontrolled donation after circulatory determination of death donor: moving to other countries. Am J Transplant 2016;16:1051-2.

18. Sabashnikov A, Patil NP, Popov AF, et al. Long-term results after lung transplantation using organs from circulatory death donors: a propensity score-matched analysis. Eur J Cardiothorac Surg 2016;49:46-53.

19. Dark JH. Lung transplantation from donation after cardiocirculatory death: the end of the golden era? Eur J Cardiothorac Surg 2016;49: $53-4$ 